\title{
Comparison of Strontium Ranelate and Alendronate Sodium Treatment among Post-Menopausal Women
}

\author{
Unal Eren ${ }^{1}$, Tuba Eren ${ }^{2}$ \\ ${ }^{1}$ Obstetrics and Gynecology Department, Trakya Hospital, Edirne, Turkey \\ ${ }^{2}$ Pediatrics Department, Trakya University, Edirne, Turkey \\ Email: unal_1@yahoo.com
}

Received 25 June 2014; accepted 13 February 2016; published 16 February 2016

Copyright (C) 2016 by authors and Scientific Research Publishing Inc.

This work is licensed under the Creative Commons Attribution International License (CC BY). http://creativecommons.org/licenses/by/4.0/

(c) (i) Open Access

\begin{abstract}
Growing rates of osteoporosis in the whole world is a serious health problem. As the "expected lifetime" is prolonged, population of elderly women with chronic diseases who require long-term treatment increases. This study aimed to compare antiresorptive treatment-that has become a classic treatment in the light of Canadian Guideline for osteoporosis-with the antiresorptive plus osteoblastic activity inducing treatment modality. The clinical and laboratory results of patients treated with a single dose of $2 \mathrm{mg}$ Strontium ranelate sachet (Protelos ${ }^{\circledR}$ ) or alendronate sodium used weekly $70 \mathrm{mg}$ tablet (Fosamax $®$ once a week tablet) for 12 -months were compared. Treatment compliance has been questioned. A hundred women in post-menopausal period were included in this study. Patient satisfaction survey among the group of strontium ranelate was unsatisfactory. Among patients using alendronate sodium the ease of use in this sense obtained a rate of $91 \%$ satisfaction from patients.
\end{abstract}

\section{Keywords}

Osteoporosis, Menopause, Strontium Ranelate, Alendronate Sodium

\section{Introduction}

Growing rates of osteoporosis in the whole world is a serious health problem. As the "expected lifetime" is prolonged, population of elderly women with chronic diseases who require long-term treatment increases [1]. In this sense, osteoporosis is a problem causing serious economic burden on the health budget because of

\footnotetext{
"Corresponding author.
}

How to cite this paper: Eren, U. and Eren, T. (2016) Comparison of Strontium Ranelate and Alendronate Sodium Treatment among Post-Menopausal Women. Open Journal of Obstetrics and Gynecology, 6, 103-106. 
compelling reasons for the long term treatment. Nowadays new formulations are emerged in the treatment and growing desire of getting short-way results is acceptable. Osteoporosis treatment using strontium ranelate has brought a new breath in the "osteoporosis treatment” with both osteoclastic activity repress and the induction of bone osteoblastic activity.

In vitro, strontium ranelate: increases bone formation in bone tissue culture as well as osteoblast precursor replication and collagen synthesis in bone cell culture and reduces bone resorption by decreasing osteoclast differentiation and resorbing activity. This results in a rebalance of bone turnover in favour of bone formation. The absolute bioavailability of strontium is about 25\% (range 19\% - 27\%) after an oral dose of 2 g strontium ranelate. Maximum plasma concentrations are reached 3 - 5 hours after a single dose of $2 \mathrm{~g}$. Steady state is reached after 2 weeks of treatment. Intake of strontium ranelate with calcium or food reduces the bioavailability of strontium by approximately 60\% - 70\%, compared with administration 3 hours after a meal. Due to the relatively slow absorption of strontium, food and calcium intake should be avoided both before and after administration of strontium. Oral supplementation with vitamin D has no effect on strontium exposure [2].

We aimed to compare antiresorptive treatment-that has become a classic treatment with in the light of Canadian Guideline for osteoporosis-with the antiresorptive plus osteoblastic activity inducing treatment modality [3]. This study is executed in postmenopausal women that have osteoporosis that is not related to a secondary cause (like chronic disease, medicine related osteoporosis, long-term cortisone use etc.) and never received hormonal therapy. The clinical and laboratory results of patients treated with a single dose of 2 mg Strontium ranelate sachet (Protelos ${ }^{\circledR}$ ) or alendronate sodium used weekly $70 \mathrm{mg}$ tablet (Fosamax ${ }^{\circledR}$ once a week tablet) for 12-months were compared. Treatment compliance has been questioned.

\section{Methods}

Between January 2010-March 2012 patients who admitted to Obstetrics and Gynecology Department in postmenopausal period were enrolled in this study. Postmenapousal women not menstruated for at least two years and not received hormonoteraphy were included. Patients with history of vertebra or hip fracture or accompanying osteoporosis related systemic diseases (thyroid disease, asthma and a chronic story of corticosteroid use) and previous use of calcium in the last one year period were excluded. None of the patients had history of anti-osteoporotic treatment before. Totally 100 patients were enrolled in this study and divided in to two groups as; 50 patients for strontium ranelate group (Group I) and 50 for alendronate sodium group (Group II). Groups were homogenized to mean age, and BMD (Bone Marrow Density) T-score and Z-score values and the average elapsed time in menopause.

Calcium (Osteocare ${ }^{\circledR}$ ) was administered in both groups with ready formulated calcium tablet form, twice a day including $800 \mathrm{mg}$ calcium, $300 \mathrm{mg}$ Magnesium, $10 \mathrm{mg}$ Zinc and 5 mcg Vitamin D (200 IU). Lumbal-lateral (LL), anterior-posterior (AP) or hip (H) was evaluated by DEXA. Anti-resorptive treatment was administered to the patients with BMD $T$-score $<-2.5$ at least in one region. In 12 months time period initially and at the end of the study the L2-3 (lumbal-lateral), L1-4, L2-4 (lumbal-AP) proximal femur BMD T-score and Z-score values were compared by DEXA method using Halogic QDR 4500 fan beam DXA collimatory device. Student's t-test was used for statistics with SPSS 17.0 (Statistical Package for the Social Sciences). Clinical fracture history and patterns of back pain, medication questions and overall patient satisfaction were recorded and calculated as percentages.

\section{Results}

Totally 100 patients were enrolled in this study and homogenized in to two groups as; 50 patients for strontium ranelate group (Group I) and 50 for alendronate sodium group (Group II). The mean age of patients in both study groups for 52 years (48 - 56) and the mean elapsed time since the last menstruation was 32 months (24 63). The mean age was 54 years for strontium ranelate group (Group I) and 52 for group alendronate sodium (group II). Mean time passed since the last menstruation period for first group (strontium ranelate) was 28.3 months and in the second group (alendronate sodium) this time period was 30.2 months. Mean BMI (Body mass index) values for Group I was $24.3 \pm 2.3$ and $25.4 \pm 1.8$ for Group II. None of the patients (which applies to both groups) did not receive either calcium preperation nor hormone therapy in the last one year period. Previously, none of the patients had no history of osteoporosis treatment and history of accompanying chronic disease which could be a cause of osteoporosis. Study continued for 12 months as planned. 3 patients left the study in stron- 
tium ranelate group (Group I). The quit of 3 patients in Group I was questioned and 2 of the patients stated the the gastric side effects and in one patient the reason was the difficulties in style of Protelos ${ }^{\circledR}$ use (Every day, during night). In the strontium ranelate group (Group I) treatment noncompliance rate was calculated as $6 \%$ (3/50). None of the patients in the alendronate sodium treatment (Group II) group quited from the study. Patients in the strontium ranelate group treatment that left study continued to receive calcium once a day for totally 12 months. The initial average BMD t-scores for lumbal-lateral, lumbal-AP and proximal-femur was $-2.7 \pm 0.2$, $-2.4 \pm 0.3$ ve $-1.9 \pm 0.1$ respectively among the patients initially for all groups. Among strontium ranelate group (Group I) the initial lumbal-lateral, lumbal-AP and proximal-femur BMD t-scores was $-2.8 \pm 0.1,-2.6 \pm 0.3$ and $-1.8 \pm 0.2$ respectively. In alendronate sodium group (DEXA performed in the same regions in order) the initial BMD t-scores were $-2.6 \pm 0.1,-2.7 \pm 0.2$ ve $-1.9 \pm 0.3$ respectively. In the analysis with Student's T-test after 12 months treatment in the strontium ranelate group lumbal-lateral, lumbal-AP and proximal-femur were $-2.7 \pm 0.2,-2.4 \pm 0.3$ and $-1.9 \pm 0.1$ respectively. The changes in the BMD $T$-scores did not reach statistical signifiance. As a percentage the lumbal-lateral $+3.5 \%$, lumbal-AP $+12.3 \%$ and for proximal-femur $t$-scores change were calculated as $-5.5 \%$. None of the alendronate sodium $70 \mathrm{mg}$ per week using patients give up treatment. The average t-score of patients after 12 months measurement was for lumbal-lateral, lumbal-AP and proximal-femur region $-2.1 \pm 0.2,-2.1 \pm 0.1$ and $-1.6 \pm 0.2$ respectively. In the alendronate using group, after -12 months analysis - the change of t-scores positively of all three DEXA regions reached statistical significance $(\mathrm{p}<0.05)$. As a percentage the change rate was $+19.2 \%$ for lumbal-lateral, $+22.1 \%$ for lumbal-AP and $+15.7 \%$ for proximal-femur. In both treatment groups there was no any clinical and radiological shown bone fracture. After 12 months treatment patient compliance and overall treatment satisfaction was questioned by physicians with face to face interviews and questions and answers were recorded. In the strontium ranelate group the question “Are you generally satisfied with the treatment?” was answered 68\% YES, while 30\% NO and $2 \%$ of patients answered indecisive. In the sodium alendronate group the patients answered this question as 91\% YES, 6\% NO and 3\% as indecisive. The question "Is the usage method (the way and timing) of the medication is appropriate for you?" was answered $86 \%$ NO in the strontium ranelate group and $14 \%$ NO in the alendronate group. 3 patients from strontium ranelate treatment group gave up treatment. The average quit duration was 3 months in this group. After 12 months back pain was questioned by asking "Do you have back pain?". In strontium ranelate group 8 patients (16\%) gave the answer YES to these questions (8/50) and 7 patients (14\%) in the sodium alendronate group (7/50).

\section{Conclusion}

Osteoporosis is associated with serious consequences like increased risk of fracture. These consequences present an increasing financial burden to healthcare systems [4]. Osteoporotic fractures of hip, wrist and vertebra have relationship with chronic pain, disability, increased mortality, and diminished quality of life. Cure is not possible especially with accompanying vertebra and femur fractures. The treatment decision for osteoporosis is directly associated with DEXA using bone dansitometry method (BMD). DEXA is not still an excellent method but it is easy to use, easy accessible, with long-term experience and the $T$-score and Z-scores that differ among races are generally standardized because of long experience period. The new methods to obtain the exact bone densitometry like bone biopsy etc. are appreciative but still not practical. Both gynecologist and other physicians are involved in osteoporosis treatment procedure. Unlike SOTI and TROPOS study [2] including strontium ranelate, our study comparing strontium ranelate with sodium alendronate did not support strontium ranelate. In the SOTI study 1649 postmenopausal women and in the TROPOS study 5091 postmenopausal women used strontium ranelate $2 \mathrm{gr} / \mathrm{day}$. The limitation of our study is the relatively small sample size $(\mathrm{n}=100)$, but the groups were selected homogeneously. The average age of patients both in the SOTI and TROPOS study was about 70 while our study population was relatively young (mean 52). The change in BMD T-scores after 12 months is not statistically significant $(\mathrm{p}<0.05)$ in lumbal-lateral and lumbal-AP regions and the hip (proximal-femur) scores were in negative trends. Patient satisfaction survey among the group of strontium ranelate was unsatisfactory. In group II, the ease of use in this sense obtained a rate of $91 \%$ satisfaction from patients.

\section{References}

[1] NIH Consensus Development Panel on Osteoporosis, Prevention, Diagnosis, and Therapy (2001) Osteoporosis Prevention, Diagnosis, and Therapy. JAMA, 285, 785-795. http://dx.doi.org/10.1001/jama.285.6.785 
[2] Reginster, J.Y., Seeman, E., De Vernejoul, M.C., et al. (2005) Strontium Ranelate Reduces the Risk of Nonvertebral Fractures in Postmenopausal Women with Osteoporosis: TROPOS Study. Journal of Clinical Endocrinology, 90, 2816-2822.

[3] Ioannidis, G., Thabane, L., Gafni, A., Hodsman, A., Kvern, B., Johnstone, D., Plumley, N., Salach, L., Jiwa, F., Adachi, J.D. and Papaioannou, A. (2008) Optimizing Care in Osteoporosis: The Canadian Quality Circle Project. BMC Musculoskelet Disord, 9, 130.

[4] Lorenc, R.S. and Resch, H., on Behalf of the Members of the " $2^{\text {nd }}$ Summit on Osteoporosis-Central and Eastern Europe (CEE)" (2009) Management of Osteoporosis in Central and Eastern Europe (CEE): Conclusions of the "2nd Summit on Osteoporosis-CEE”, 21-22 November 2008, Warsaw, Poland. Archives of Osteoporosis, 4, 1-8. http://dx.doi.org/10.1007/s11657-009-0028-6 